\title{
CURADORIA DAS COLEÇÕES ARQUEOLÓGICAS PRÉ-HISTÓRICAS BRASILEIRAS NO MAE/USP
}

O Museu de Arqueologia e Etnologia da Universidade de São Paulo mantém coleções de arqueologia pré-histórica brasileira, principalmente do Estado de São Paulo, coletadas em pesquisas arqueológicas de campo, desde a década de 50 até hoje, reunindo, assim, um acervo importante para a compreensão das ocupações pré-históricas no território brasileiro.

A necessidade e a urgência em organizar e gerenciar este valioso acervo de uma forma institucional levaram à elaboração do projeto Organização e gerenciamento do acervo arqueológico préhistórico brasileiro do Museu de Arqueologia e Etnologia da Universidade de São Paulo. Este projeto, de cunho curatorial, iniciou-se no primeiro semestre de 1997, com o apoio financeiro da Fundação de Amparo à Pesquisa do Estado de São Paulo (FAPESP).

Nas últimas décadas, museus do mundo inteiro intensificaram suas discussões com relação ao destino e à organização dos acervos acumulados nas reservas técnicas, motivados por seu grande e crescente volume, uma vez que materiais de diversas categorias provenientes de pésquisas arqueológicas de campo chegam regularmente, passam por um processo de tratamento, identificação, análise e são armazenados na reserva técnica onde permanecem à disposição para o uso em pesquisa, ensino e atividades de extroversão museológica.

Em decorrência deste acúmulo, os museus discutem normas sobre métodos de coleta, possibilidade de descarte e "planejamento por meio da definição de uma política de acervo, traçada a partir do próprio estudo das coleções existentes e dos problemas científicos inspirados pelas mesmas" (Bruno 1995).

Os profissionais do Museu de Arqueologia e Etnologia da Universidade de São Paulo, desde a fusão em 1989, vêm discutindo um sistema de gerenciamento do acervo constituído de coleções arqueológicas e etnográficas provenientes dos setores de Arqueologia e Etnologia do Museu Paulista, dos antigos Instituto de Pré-História e Museu de Arqueologia e Etnologia e do Acervo Plínio Ayrosa
(Departamento de Antropologia da Faculdade de Filosofia, Letras e Ciências Humanas).

O MAE abriga grande parte do material proveniente de pesquisas arqueológicas no Estado de São Paulo e com a obtenção de espaço, mobiliário e equipamentos adequados o momento atual é oportuno para a realização de um projeto de organização e gerenciamento do acervo.

Outros museus brasileiros também estão desenvolvendo projetos curatoriais, como o Museu Arqueológico de Sambaqui de Joinville (MASJSanta Catarina) e o Museu Nacional de Belas Artes (MNBA-Rio de Janeiro), demonstrando que cada vez mais os profissionais de museus estão preocupados com o gerenciamento e a utilização dos acervos culturais. Este interesse está provocando reflexos nas agências financiadoras de pesquisa como a VITAE e a FAPESP que vêm patrocinando projetos de documentação e conservação de acervos.

O projeto curatorial do MAE visa normatizar o controle das peças e de suas informações, sem as quais perdem sentido e significação. Este projeto objetiva controlar, preservar e recuperar tanto as peças quanto sua respectiva informação. Após este trabalho, o acesso a este material será facilitado, permitindo sua divulgação e estudos por parte de pesquisadores do museu e de outras instituições, estudantes de vários níveis, público do museu e demais interessados. Somente através do controle e sistematização será possível cumprir plenamente a missão institucional do MAE/USP relacionada à divulgação e à extroversão do conhecimento ali produzido e desenvolvido.

$O$ projeto pretende, através da implantação de um sistema controlado, unificar a linguagem de acesso aos objetos arqueológicos, bem como às informações respectivas, além de conhecer com precisão a quantidade e a potencialidade do acervo. Este sistema controlado implica na definição de critérios de identificação, organização, registro, preservação e recuperação de dados sobre as coleções existentes.

Está direcionado às reais necessidades de tratamento das coleções arqueológicas e baseia-se nas 
experiências dos membros da equipe, tanto na área de arqueologia quanto na de gerenciamento e gestão de informações de âmbito museológico.

Seu suporte científico está assentado em análises feitas com o material existente e no aproveitamento dos resultados de projetos anteriores já avaliados. Apresenta-se como uma solução possível para o caso específico do MAE/USP apoiada na literatura internacional relativa ao tratamento, gerenciamento e documentação de gestão de coleções arqueológicas abrigadas em espaços museológicos (Hitchcock 1980, King 1980, Novick 1980, Wilcox 1980, Yang 1989, entre outros).

Em um primeiro momento, o projeto visa organizar o acervo arqueológico pré-histórico brasileiro já analisado por arqueólogos e depositado na sede do MAE/USP e no Centro Regional de Pesquisas Arqueológicas Mário Neme/MAE, situado na cidade de Piraju (SP). Este recorte curatorial da coleção foi escolhido por se tratar da maior parte do acervo em termos numéricos e o que mais aumenta, além de apresentar diversificação de materiais e variadas formas de documentação primária.

Este acervo nunca passou por um processo de documentação de gestão museológica, tendo sido coletado e organizado pelos próprios arqueólogos responsáveis pelos projetos de pesquisa. Há cada vez mais profissionais preocupados com a grande quantidade de objetos e dados provenientes das pesquisas e, segundo Pebbles \& Galloway (1981), “...there are two crucial challenges offered by all these data that have not been met: 1) appropriate and efficient data management, and 2) long-term documentation and adequate curatorial facilities"

A implantação do projeto deve ser entendida dentro das peculiaridades vinculadas à natureza dos vestígios que, a partir da especificidade da coleta, estudo e organização, impõe procedimentos diferenciados em relação aos outros segmentos patrimoniais do MAE. O resultado deste trabalho permitirá uma avaliação de procedimentos e eventuais adaptações para otimizar o tratamento das outras coleções que compõem o acervo.

$O$ projeto tem os seguintes objetivos:

1. definir uma sistemática de trabalho que atenda às peculiaridades do acervo pré-histórico brasileiro, a fim de preservar e conservar estes vestígios patrimoniais;

2. organizar a documentação primária proveniente das pesquisas de campo e laborató- rio (fichas de campo, mapas, fotos, diapositivos, filmes, croquis, etc.);

3. possibilitar o controle dos acervos e documentação correspondente, no que diz respeito à recuperação dos mesmos, permitindo estudos e processos de extroversão museológica;

4. acondicionar as coleções arqueológicas na Reserva Técnica.

Pretende-se desenvolver os trabalhos nas 170 coleções provenientes de pesquisas arqueológicas sistemáticas, aplicando uma estratégia de trabalho que visa otimizar a potencialidade de informação de "conjuntos" que já foram submetidos a algum procedimento científico por parte dos arqueólogos.

Quatro etapas foram previstas e já iniciadas:

Primeira etapa: Levantamento dos projetos de pesquisa desenvolvidos ou em desenvolvimento no MAE/USP, por meio do controle e registro em fichas específicas de cadastramento e a formação de um Banco de Dados informatizado, que possibilitará a elaboração do diagnóstico e a apresentação das bases de gerenciamento aplicado desta informação, traçando o perfil organizacional da reserva técnica, do arquivo e da documentação de gestão museológica.

Segunda etapa: localização das coleções, levando em consideração os projetos a que pertencem e a natureza do material (lítico, cerâmico, ósseo humano, osteodontomalacológico, restos alimentares, sedimentos, amostras para datação, etc.). Paralelamente, a documentação primária constituirá o arquivo de pesquisa do setor, de caráter institucional. Nesta etapa, serão realizados a determinação topográfica e resgate das coleções, a seleção do material a ser depositado na reserva técnica e no arquivo, a limpeza e tratamento dos artefatos, o inventário controlado e padronizado dos objetos, a embalagem e armazenamento em locais apropriados.

\section{Terceira etapa: Informatização dos dados}

Quarta etapa: avaliação dos procedimentos, métodos e elaboração do relatório

Uma coleção foi escolhida para servir como modelo de análise: a do sambaqui Piaçaguera, escavado na década de 60 pelos Profs. Drs. Dorath Pinto Uchôa e Caio del Rio Garcia, por apresentar materiais de diversas categorias (líticos, ósseos, restos esqueletais, restos faunísticos), ter uma 
excelente e bem organizada documentação primária, além de ter sido objeto de análises sistemáticas.

Esta nota tem a intenção de apresentar o projeto curatorial em desenvolvimento e espera- se que sua metodologia de trabalho possa vir a ser aplicada tanto aos outros segmentos do acervo do MAE quanto ao material proveniente de pesquisas arqueológicas de campo, que regular e incessantemente, é salvaguardado pela instituição.

\section{Referências bibliográficas}

\section{BRUNO, M.C.O.}

1995 Musealização da arqueologia: um estudo de modelos para o projeto Paranapanema. Tese de doutorado apresentada na FFLCH/USP.

KING, M.E.

1980 Curators: Ethics and Obligations. Curator 23(1): 10-18.7.

\section{HITCHCOCK, A.}

1980 Discussion Paper. Curator 23(1): 71-79.

NOVICK, A.L.

1980 The management of archaeological documentation. Curator 23(1): 30-42.
PEEBLES, C.S.; GALLOWAY, P.

1981 Notes from underground: archaeological data management from excavation to curation. $\mathrm{Cu}$ rator 24(4): 225-251.

WILCOX, U.V.

1980 Collections management with the computer. $\mathrm{Cu}$ rator 23(1): 43-54.

YANG, $M$.

1989 Manuals for Museum Policy and procedures. Curator 32(4): 269-274.
Marisa Coutinho Afonso* Marilúcia Bottallo** Silvia Cristina Piedade*** José Luiz de Morais*

Recebido para publicação em 18 de setembro de 1997.

(*) Museu de Arqueologia e Etnologia da Universidade de São Paulo.

(**) Museu de Arqueologia e Etnologia da Universidade de São Paulo, Serviço de Curadoria, Equipe Técnica de Documentação.

(***) Especialista em Pesquisa de Apoio em Museus. Financiamento FAPESP. 